\title{
O DESENVOLVIMENTO DE PROCESSOS DE INOVAÇÃO SOB A ÓTICA DA TEORIA DOS CUSTOS DE TRANSAÇÃO: O CASO DA TECNOLOGIA FLEX-FUEL
}

\author{
Daniel Leite Mesquita \\ Doutorando em Administração pela Universidade Federal de Lavras \\ mdleite@gmail.com (Brasil)
}

\author{
Alex Fernando Borges \\ Doutorando em Administração pela Universidade Federal de Lavras \\ Professor da Universidade Federal de Uberlândia \\ alexfborges@gmail.com (Brasil)
}

\section{Joel Yutaka Sugano}

Doutor em Administração - Osaka University, Japan

Professor da Universidade Federal de Lavras

joel.sugano@gmail.com (Brasil)

\section{Antônio Carlos dos Santos}

Doutor em Administração pela Universidade de São Paulo

Professor da Universidade Federal de Lavras

acsantos@dae.ufla.br (Brasil)

\section{RESUMO}

Este trabalho foi realizado com o objetivo de analisar o surgimento da tecnologia flex-fuel sob a perspectiva dos custos de transação. Para tanto, foram entrevistados os principais atores envolvidos no seu desenvolvimento, articulando-se quatro categorias para identificar como se estruturaram custos de transação: racionalidade limitada, frequência da transação, especificidade de ativos e oportunismo. Foi possível concluir que as montadoras tiveram capacidade de elaborar contratos mesclando relações híbridas entre mercado e hierarquia. A partir disso, a contribuição principal deste estudo consiste na análise de custos de transação no desenvolvimento da tecnologia flex-fuel, fato pouco estudado na academia brasileira.

Palavras- chave: Custos de transação; Tecnologia flex-fuel; Inovação. 


\section{INTRODUÇÃO}

O movimento de retomada de investimentos e de atualização tecnológica, viabilizado pelos processos de globalização, tem sido a base para o surgimento de novas configurações estratégicas e de novas transações entre as organizações da indústria automobilística, abrindo espaço para a inovação e para a criação de novos produtos e novas tecnologias automotivas. Essas mudanças provocaram profundas modificações nas estruturas de governança da indústria automobilística, que repercutiram diretamente nas relações interorganizacionais entre montadoras e fornecedores (Ferrato, Carvalho, Spers, \& Pizzinatto, 2006). Assim, os impactos tecnológicos nesse setor refletiram em um automóvel cada vez mais complexo, o qual passou a ser produzido com a participação ativa de diversos fornecedores (Womack, Jones, \& Roos, 2004).

Conforme Torres (2011), a organização atual da produção mundial de automóveis caracterizase pela dispersão para os mercados emergentes, tanto das montadoras quanto das fornecedoras de autopeças. O investimento estrangeiro foi direcionado para países como Brasil, China e Índia, em função da saturação e do aumento da concorrência nos mercados desenvolvidos, e pelo potencial de crescimento daqueles países.

Por envolver transações e o relacionamento entre diversas organizações (montadoras e fornecedores), por ser uma tecnologia nacional e ter obtido a aceitação dos consumidores, a chamada tecnologia flex-fuel foi o foco deste estudo. De acordo com Consoni (2004), a iniciativa do desenvolvimento de veículos com a tecnologia flex-fuel ofereceu respostas às demandas locais de mercado e envolveu, de forma importante, a cooperação entre montadoras e fornecedores atuantes no Brasil. Nesse contexto, a abordagem da teoria dos custos de transação (TCT) pode ser utilizada nesse campo para avaliar a qualidade das relações entre compradores e vendedores (montadoras e fornecedores) e o valor do desenvolvimento de parcerias e confiança entre eles (Alves, Cerra, Maia, Sacomano, \& Bonadio, 2004). A TCT considera as implicações organizacionais em desenvolver uma transação internamente à empresa, no mercado ou por meio de formas híbridas (Maia \& Cerra, 2008).

Sendo assim, este trabalho foi realizado com o objetivo de analisar o surgimento da tecnologia flex-fuel sob a perspectiva da teoria dos custos de transação (TCT), Para tanto, foi realizada uma pesquisa qualitativa de cunho exploratório, devidamente fundamentada a partir da realização de entrevistas semiestruturadas em profundidade com os principais atores envolvidos no processo de desenvolvimento da tecnologia flex-fuel. Em termos específicos, os dados foram articulados e analisados sob a perspectiva de quatro categorias distintas: racionalidade limitada, frequência da Revista de Administração e Inovação, São Paulo, v. 10, n.1, p. 119-140, Jan./Mar. 2013. 
transação, especificidade de ativos e oportunismo. Esta forma de abordagem do problema se justifica, uma vez que, para o desenvolvimento da tecnologia, houve participação direta de fornecedores e interação constante com as montadoras, estabelecendo formas específicas de relação entre mercado e hierarquia (Mello, Vasconcellos, \& Marx, 2005, 2006; Teixeira, 2005). A partir disso, a contribuição principal deste estudo consiste na análise de custos de transação no desenvolvimento da tecnologia flex-fuel, fato pouco estudado na academia brasileira.

O presente artigo está estruturado, além desta introdução, em sessões intituladas teoria dos custos de transação, tecnologia flex-fuel a indústria automobilística brasileira, procedimentos metodológicos, tecnologia flex-fuel na abordagem da teoria dos custos de transação, considerações finais e referências.

\section{TEORIA DOS CUSTOS DE TRANSAÇÃO (TCT)}

A teoria dos custos de transação compreende a firma e, consequentemente, suas estratégias como um problema de governança. Isso significa dizer que as estratégias e a ação das firmas dependem do modo como estas organizam as transações. Dito de outra forma, as firmas podem optar por buscar seus bens no mercado ou organizar estruturas internas (hierarquias) para produzir seus bens. Assim surgem questões relevantes nesse contexto, tais como: O que buscar no mercado? Que atividades realizar dentro da própria firma? Desse modo, considera-se a complexidade das organizações e de suas transações, destacando-se a eficiência da firma de acordo com a melhor forma de governança (Seth \&Thomas, 1994).

Os problemas de transação podem ser contornados pelas estruturas de governança, ou seja, o conjunto de regras representadas pelas instituições. Mercados e hierarquias, e formas híbridas, como as redes e contratos, são chamados de mecanismos de governança. As formas de governança de mercado dependem do preço, da competição e dos contratos para manter todas as partes interessadas em uma transação, informadas de seus direitos e responsabilidades. Formas hierárquicas de governança, por outro lado, reúnem as partes de uma transação sob o controle direto de terceiros. Essa autoridade tenta manter todas as partes envolvidas numa transação, informadas de seus direitos e responsabilidades. Os agentes econômicos escolherão a forma de governança que reduza os possíveis problemas de transação ao menor custo possível, de acordo com as frequências da transação e da especificidade de ativos (Kupfer \& Hasenclever, 2002).

Revista de Administração e Inovação, São Paulo, v. 10, n.1, p. 119-140, Jan./Mar. 2013. 
Dessa maneira, a Teoria dos Custos de Transação trata, basicamente, da escolha da forma organizacional mais adequada para a minimização de custos. Barney e Hesterly (2006) afirmam que os agentes econômicos devem escolher a forma de governança que reduza os possíveis problemas de transação ao menor custo possível. Em síntese, as firmas podem incorrer em custos internos elevados ao adotarem estruturas hierárquicas, ou serem vitimas de práticas oportunistas pela coordenação via mercado (Barney \& Hesterly, 2006).

Williamson (2005) ressalta que os custos de transação são relevantes devido a: (1) sua plausibilidade, com referencia à descrição dos atores e seus mecanismos de funcionamento; (2) sua orientação aplicada com ênfase sobre a governança das relações contratuais; (3) seu processo de orientação intertemporal com ênfase em problemas contínuos; (4) sua base interdisciplinar no Direito, Economia e organizações e (5) sua insistência em implicações refutáveis e no teste empírico. Para a TCT, há um conjunto de variáveis que explicam teoricamente a ocorrência dos custos de transação, que são os custos associados à administração do sistema econômico. Tais variáveis, consideradas como categorias analíticas, são racionalidade limitada, frequência da transação e especificidade de ativos. Rodrigues, Aguiar e Macohin (2004) definem esses elementos da seguinte forma:

- racionalidade limitada: a recepção, a armazenagem e o processamento da informação apresentam, por parte dos participantes da relação de transação, limites relativos ao seu nível de conhecimento e de habilidades, acarretando, então, distúrbios inesperados às transações e consequentes acréscimos nos custos de transação;

- frequência da transação: é importante para determinar a possibilidade de internalizar ou não determinada etapa produtiva sem perder a eficiência relacionada à escala. Se a frequência é alta, a recorrência das transações torna mais rápida a recuperação do investimento via mercado. Se a frequência é baixa com transações não recorrentes, promove-se a hierarquia de atividades. Assim, a frequência tem relevância para explicar a estrutura de controle, pois, quanto mais frequente uma transação, mais uma estrutura especializada pode se manter;

- especificidade de ativos: grau pelo qual um ativo aumenta a dependência entre as partes, produzindo efeitos diretos na definição das regras do relacionamento, inclusive em termos de repartição de resultados, já que o investimento realizado por uma das partes em relação à outra deve ser, de alguma forma, recompensado. Assim, quanto maior a especificidade de ativos, maior a tendência à internalização da atividade considerada. Do contrário, há a utilização dos mecanismos de mercado ou de modos híbridos de transação, como os contratos ou redes. A Revista de Administração e Inovação, São Paulo, v. 10, n.1, p. 119-140, Jan./Mar. 2013. 
especificidade de ativos pode ser caracterizada, de acordo com McIvor (2009), em: especificidade humana (nível de conhecimento especializado envolvido na transação); especificidade física (nível de customização do produto ou serviço) e especificidade locacional (local da transação).

Costa, Carvalho e Thomé (2008) ressaltam mais um elemento advindo da TCT: o oportunismo, que pode advir da assimetria informacional (diferença de informação entre as partes):

A informação assimétrica e o custo de aquisição da informação geram oportunismo antes da transação (ex ante ou seleção adversa) e após da transação (ex post ou risco moral). O primeiro tipo corresponde aos custos com obtenção da informação, negociações e garantias antes da ocorrência da transação, o segundo corresponde aos custos para monitorar a transação, ajustar contratos e reparar danos causados por falhas contratuais. O comportamento oportunista pode levar um agente a quebrar um contrato estabelecido, ou ocultar uma informação estratégica para obter vantagem individual, obtendo poder de especialidade diante do outro membro da relação (Costa et al., 2008, p. 7).

Esses elementos podem ser verificados na indústria automobilística no Brasil. Em seu estudo, Maia \& Cerra (2008) constataram que, no país, as montadoras utilizam uma relação híbrida com seus fornecedores, mesclando uma concorrência latente e momentos de cooperação, o que afeta diretamente a assimetria informacional entre as partes. Os autores também observam que os volumes da transação e a maximização de investimentos afetam a especificidade de ativos e a existência de oportunismo. Sendo assim, pretende-se, nas próximas sessões deste artigo, discutir os diferentes formatos de relacionamentos na indústria automobilística, bem como discorrer sobre a perspectiva da tecnologia flex-fuel no Brasil.

\section{TECNOLOGIA FLEX-FUEL E A INDÚSTRIA AUTOMOBILÍSTICA BRASILEIRA}

Nesta sessão o objetivo é demonstrar como são construídos os diferentes relacionamentos na indústria automobilística e como estes relacionamentos constituíram a base para a configuração, o surgimento e a evolução da tecnologia flex-fuel no Brasil. 
Toledo et al. (2001 citado em Cerra, 2005) sustentam que o processo de desenvolvimento de produtos na indústria automobilística tem três modalidades distintas de projeto com as seguintes características e tipologias:

- no primeiro modelo, a peça, ou sistema, é desenvolvida e fabricada somente pelo fornecedor, sem qualquer controle por parte da montadora, possibilitando redução de custos do fornecedor, que pode vender o mesmo item a vários clientes;

- o segundo tipo são projetos de característica black box, nos quais a montadora estipula parâmetros de desempenho e delega $100 \%$ do desenvolvimento e da produção a fornecedores. Conforme Vieira (2001), esses projetos pressupõem uma forma de envolvimento dos fornecedores com a montadora no desenvolvimento completo de peças/módulos com contratos mais longos, qualificação e capacitação dos mesmos;

- por fim, os projetos de produtos conhecidos como gray box são aqueles definidos pela montadora (cliente), nos quais ocorre estritamente o processo de fabricação pelos fornecedores. Conforme Dias e Salerno (1998), esse caso ocorre em componentes de menor valor para as montadoras, uma vez que as requisições dos produtos são recebidas em um pacote de especificações para o fornecedor, ficando também sob sua responsabilidade o custo do desenvolvimento do processo de fabricação.

De acordo com Crispim e Toledo (2003), as montadoras utilizam as seguintes práticas para se aproximar dos fornecedores:

- global sourcing: a montadora busca fornecedores que atendam às exigências de preço e de qualidade. Estes fornecedores mantêm contato direto com as montadoras e podem assumir maiores responsabilidades, inclusive sobre o desenvolvimento de produtos;

- follow sourcing: nesta modalidade, o fornecedor que desenvolveu uma peça pela primeira vez fornece o mesmo item a todas as plantas do grupo da montadora que produzirem o veículo. Conforme Aguiar (2001), o fornecedor segue a montadora de veículos por todo o mundo, instalando novas fábricas ou fornecendo a partir de fábricas já instaladas em outros países;

- codesign: há compartilhamento no projeto de desenvolvimento do produto entre fornecedores e a montadora. Em alguns casos, assumindo por inteiro o desenvolvimento de produtos, nas Revista de Administração e Inovação, São Paulo, v. 10, n.1, p. 119-140, Jan./Mar. 2013. 
condições de qualidade e prazo estipuladas pela montadora, ocorre também a troca de know-how entre montadora e fornecedor;

- parcerias: permitem ao fornecedor assumir grande parte das atividades, até então de domínio das montadoras, no processo produtivo e de montagem dos veículos por meio de contratos longos, como é o caso do consórcio modular;

- relações de proximidade: referem-se à localização física do fornecedor com relação à montadora e relaciona-se especificamente a problemas de logística;

- carry-over-parts: a montadora utiliza peças ou conjuntos já desenvolvidos em projetos anteriores, no novo projeto de veículo.

Com a necessidade de especialização em determinadas competências trazidas pela evolução tecnológica, ocorreu uma delegação de responsabilidade ou terceirização a fornecedores. Conforme Mello et al. (2006) foi o envolvimento de fornecedores que possibilitou a inovação do automóvel bicombustível no Brasil. Devido aos conhecimentos necessários em eletrônica, a capacidade das montadoras para desenvolver a tecnologia isoladamente era improvável. Consoni (2004) afirma que o sistema bicombustível foi desenvolvido no Brasil para atender às demandas locais, aproveitando a competência do motor a álcool já patenteada no país. Pode-se considerar essa inovação como um processo de 'tropicalização', em que se busca adaptar modelos, plataformas ou alguns módulos (como o sistema de combustíveis alternativos) às condições locais - gostos ou condições de rodagem (Dias, 2003).

\subsection{A Tecnologia flex-fuel}

A preocupação em desenvolver uma nova tecnologia que pudesse oferecer aos consumidores opções de escolha na hora de abastecer seu carro foi um fator importante para o surgimento da tecnologia flex-fuel. Isto porque o motor flex reduz a dependência por um único combustível e permite aos consumidores levar em conta o melhor preço ao abastecer o carro. Nesse sentido, as pesquisas de um motor 'flexível' visavam propiciar a viabilidade econômica da frota de veículos multicombustíveis, beneficiando diretamente o consumidor final e o mercado.

Os estudos que visavam à utilização do metanol nos Estados unidos e do etanol no Brasil serviram como base para o desenvolvimento do primeiro conceito de um motor flex. De forma geral, o 'motor flex' é composto por um sensor eletrônico na linha de combustível, que mede o teor de álcool na gasolina. $\mathrm{O}$ sensor ajusta automaticamente os componentes do motor para trabalharem com cada Revista de Administração e Inovação, São Paulo, v. 10, n.1, p. 119-140, Jan./Mar. 2013. 
mistura: o mesmo tanque, o mesmo motor e o mesmo sistema de injeção para ambos os combustíveis (Teixeira, 2005).

De acordo com Alves e Brandão (2007), o primeiro protótipo deste tipo de automóvel, no Brasil, foi lançado em 1994, baseado em tecnologia estrangeira. Nos Estados Unidos, os primeiros carros flex-fuel foram desenvolvidos em 1984, para fins experimentais e entraram no mercado no início da década de 1990, baseados numa mistura de combustível de, no máximo, 85\% de etanol anidro. Dessa forma, os primeiros veículos flex utilizavam um sensor físico de combustível, caro e inadequado ao combustível brasileiro (Teixeira, 2005). Para a adoção da tecnologia flex-fuel no Brasil, o álcool disponível era o etílico hidratado carburante, sendo necessária a adaptação às condições do país (Di Giulio, 2006).

Somente em 1999 se viabilizou comercialmente o produto com a chegada do sistema Software Flex Fuel Sensor (SFS). Totalmente desenvolvido no Brasil, utilizou-se um programa de computador inserido no módulo de comando da injeção eletrônica, fazendo com que o veículo pudesse rodar com álcool, gasolina ou qualquer mistura dos dois combustíveis. Assim, a tecnologia flex-fuel é sinônimo de flexibilidade e dá liberdade ao consumidor na escolha do combustível mais barato ou disponível (Delgado, Araujo, \& Fernandes, 2007).

O software é vendido às montadoras pelas empresas fornecedoras, que fabricam o equipamento de injeção eletrônica. No fim dos anos 1990, passaram a ser desenvolvidos softwares para o 'carro flex', com a criação de um algoritmo que calculava a composição do combustível com base nas informações colhidas pelos diversos sensores que os motores dos carros normalmente trazem (Lima, 2006). A partir dessas informações dos sensores, o programa determina a quantidade de combustível que será injetada no motor O sinal recebido através da sonda lambda, da composição dos gases resultantes da combustão, permite o ajuste a ser feito porque a central memoriza a última proporção utilizada e se encarrega, quando necessário, de acionar a partida a frio (Piacente, 2006).

Portanto, a tecnologia flex-fuel consiste em aliar elementos presentes para o funcionamento do motor do automóvel (combustível e oxigênio). A partir do sensor de oxigênio e de outros sensores existentes no motor (como o de temperatura), criou-se o eletronic control module (ECM), um algoritmo capaz de identificar o combustível e calcular se há a necessidade de queimar mais ou menos combustível. A ideia central do sensor é baseada no seguinte raciocínio: se há mais escape de oxigênio, o sensor reage queimando menos combustível; do contrário, se há uma quantidade menor de oxigênio, o sensor reage queimando mais combustível.

Revista de Administração e Inovação, São Paulo, v. 10, n.1, p. 119-140, Jan./Mar. 2013. 
Além do advento do software, outro fator que viabilizou o surgimento do veículo flex-fuel foi a adoção da alíquota do Imposto sobre Produtos Industrializados (IPI) do carro a álcool (inferior à do carro a gasolina). Assim, o primeiro carro flex nacional foi lançado pela Volkswagen, em 24 de março de 2003, Em apenas cinco anos, mais de 90\% dos veículos novos comercializados no país contavam com a tecnologia flex-fuel (Gatti \& Yu, 2011).

A primeira geração de motores flex-fuel manteve a base do conhecimento dos motores a álcool (etanol) com uma potência e taxa de compressões menores. A segunda geração procurou dar um tratamento intermediário entre o etanol e a gasolina. Na terceira geração, chegou-se ao máximo de compressão do motor para se alcançar, respectivamente, maior torque e potência. Por fim, na última geração de motores flex, tanque de gasolina ao lado do motor foi retirado do sistema, com o objetivo de melhoria de partida a frio dos veículos. Esses tipos de inovações trazem à tona as possibilidades de exportação da tecnologia flex-fuel para outros países ou em regiões mais frias do Brasil (Mesquita \& Sugano, 2011; Yu, Nascimento, Silva, Camargo, Duranti, \& Moura, 2010).

\section{PROCEDIMENTOS METODOLÓGICOS}

Esta pesquisa fundamentou-se em uma abordagem qualitativa do tipo exploratória, já que se buscou conhecer o panorama de desenvolvimento da chamada tecnologia flex-fuel e investigar os relacionamentos entre montadoras de automóveis e fornecedores envolvidos na concepção dessa tecnologia. Nessa perspectiva, foram realizadas entrevistas semiestruturadas orientadas por um roteiro, de modo a possibilitar a identificação da percepção dos diferentes atores envolvidos no processo. Neste sentido, buscou-se encontrar evidências e padrões nos dados, a partir das entrevistas realizadas, que confirmassem, ou não, as categorias de análise da Teoria dos Custos de Transação articuladas nesse artigo, quais sejam: racionalidade limitada, frequência da transação, especificidade de ativos e oportunismo.

Para a análise das entrevistas, foi proposto o método da análise de conteúdo. Para Bardin (1979), a análise de conteúdo representa técnicas de análise de comunicação que, por meio de descrição do conteúdo das mensagens, permitem a inferência de conhecimentos relativos às condições de produção/recepção destas mensagens. A análise de conteúdo é considerada uma técnica para o tratamento de dados que visa identificar o que está sendo dito a respeito de terminado tema. As características principais deste método são: presta-se tanto aos fins exploratórios quanto aos de verificação; exige categorias exaustivas, mutuamente exclusivas, objetivas e pertinentes e gera grande Revista de Administração e Inovação, São Paulo, v. 10, n.1, p. 119-140, Jan./Mar. 2013. 
quantidade de dados, que podem ser tratados com o auxílio de programas de computador (Vergara, 2006).

A análise de conteúdo teve como foco a análise temática ou categorial que funciona pela divisão do texto em unidades (frases, parágrafos). A escolha se justifica, principalmente, pela facilidade de sua aplicação nos discursos diretos, favorecendo a compreensão dos textos (Bardin, 1979). De acordo com Triviños (1987), na análise de conteúdo podem surgir premissas que se levantam como resultado do estudo de dados da comunicação. As entrevistas foram gravadas (para posterior transcrição) e tiveram duração aproximada de uma hora. Os indivíduos (dois membros de empresas fornecedora Alfa; um membro da fornecedora Gama e dois membros ligados a montadoras membro da montadora A, membro da montadora B) foram selecionados de acordo com o critério não probabilístico por julgamento pela acessibilidade e, primordialmente, pelo nível de conhecimento acerca da tecnologia flex-fuel. Os entrevistados selecionados detêm esse conhecimento e participaram do seu desenvolvimento.

\section{TECNOLOGIA FLEX-FUEL NA ABORDAGEMDATEORIA DOS CUSTOS DE TRANSAÇÃO (TCT)}

Nesta sessão, apresentam-se os resultados da pesquisa de campo. Os dados obtidos a partir das entrevistas foram compilados e analisados com base em quatro categorias referentes à teoria dos custos de transação, conforme apresentado anteriormente ao longo do referencial teórico deste trabalho: a frequência das transações, a especificidade de ativos, o oportunismo e a racionalidade limitada.

\subsection{A Tecnologia Flex-Fuel: a Frequência das Transações}

A frequência diz respeito à regularidade com que a transação ocorre no tempo, ou seja, o número de vezes em que os agentes econômicos realizam as transações. Isso implica na possibilidade de construção de reputação por parte dos agentes envolvidos na transação por meio de um maior conhecimento dos agentes entre si (Rocha, Silva, Bittencourt, \& Mascena, 2012). Devido às novas formas de relacionamento com fornecedores, distribuidores e clientes, que permitem a padronização da produção, as montadoras e as empresas de autopeças passaram a buscar padrões de relação mais estáveis com compromissos recíprocos (Segre, Roldan, \& Dumans, 1998). Inovações, como o sistema Revista de Administração e Inovação, São Paulo, v. 10, n.1, p. 119-140, Jan./Mar. 2013. 
flex-fuel, foram desenvolvidas por um fornecedor como um módulo completo fornecido às montadoras. No caso específico da tecnologia flex-fuel, as organizações fornecedoras optaram pelo desenvolvimento de sistemas de injeção eletrônica como enfoque de sua competência, mas a competência de integrar os diferentes sistemas eletrônicos e mecânicos, criando especificações e produtos com características valiosas para os clientes finais, ainda é exclusiva das montadoras (Mello et al., 2005).

No contexto da TCT, Pinheiro (1999) afirma que externalizar ou não uma atividade é o resultado de um processo decisório que contempla tanto variáveis objetivas (condições internas versus externas de preço, capacidade produtiva, qualidade, dentre outros), quanto subjetivas, a exemplo do risco implícito desta decisão. De acordo com Mello et al. (2006), a inovação do motor bicombustível envolve a modificação de diversos componentes, para que o motor seja funcional, de modo que se torna difícil delegá-la exclusivamente a fornecedores. Para a montadora, o motor é um ativo de elevada especificidade, conforme se observa no seguinte depoimento: "Nós apanhamos fornecedores que tão alinhados mais com a filosofia da (montadora). Não é só custo. É claro que o custo, é, pra você sobreviver no mercado, é fundamental, mas... Tem aquela questão de qualidade, ainda mais quando envolve motor, né? O motor é o coração do carro... tanto é que nacionalizar itens de motor, aqui no Brasil, é um 'parto"' (montadora B).

\subsection{A Tecnologia Flex-Fuel: a Especificidade de Ativos}

O desenvolvimento de sistemas eletrônicos tornou-se uma atividade em que a montadora não teria condições de concorrer com os fornecedores especializados e, a partir desse momento, as outras montadoras passaram a depender desses fornecedores, numa dependência de conhecimento (Mello et al., 2006). Nesse sentido, para a abordagem da TCT, a tecnologia da flex-fuel é um ativo que tem alta especificidade humana. De acordo com Ferreira e Serra (2010), esse modelo se baseia em relacionamentos de confiança e estabilidade que permitem o foco nas competências centrais e a redução dos custos de transação.

"[...] nasce essa parceria, onde nossos engenheiros compartilham as atividades, os ensaios, as evoluções com a montadora, discutem: 'olha eu acho que precisa fazer assim porque fizemos levantamento no laboratório, fizemos os dados aqui, as emissões são essas aqui, acho que devemos fazer... '. Nasce o processo de aperfeiçoamento, uma cadeia na verdade e nasce uma grande parceria entre a empresa fornecedora, nesse caso sistemista,como é chamado, e a montadora é uma parceira. É um, o chamado, como uma palavra em inglês, codesign que se chama" (fornecedora Alfa).

Revista de Administração e Inovação, São Paulo, v. 10, n.1, p. 119-140, Jan./Mar. 2013. 
Cerra, Maia e Alves (2007) afirmam que fornecedores, em geral, são dependentes das estratégias das montadoras, aceitando exigências quanto a especificações técnicas e qualidade dos produtos fornecidos. Essa realidade confere à tecnologia da flex-fuel um padrão a ser utilizado pelas montadoras conforme suas 'necessidades' no momento da aquisição da tecnologia, o que faz que ela seja adquirida pelas montadoras de diferentes sistemistas. Nesse sentido, para a abordagem da TCT, a tecnologia flex-fuel para as montadoras é um ativo que tem uma baixa especificidade física porque pode ser 'encontrado' no mercado com fornecedores distintos. Costa et al. (2008) afirmam que, quando a especificidade do recurso é elevada, o que se espera é que a transações ocorram dentro das organizações, e não via mercados, o que pode viabilizar praticas oportunistas.

\subsection{A Tecnologia Flex-Fuel: o Oportunismo}

A tecnologia flex-fuel teve como característica a relação direta entre fornecedores e montadoras. No que concerne à abordagem da TCT, em indústrias maduras, como a automotiva, há a tendência de se terceirizar as operações, uma vez que há fornecedores com equipamento e habilidade para conduzir a atividade, reduzindo a possibilidade de comportamentos oportunistas (Ferreira \& Serra, 2010). Nesse sentido, houve mudanças que refletiram diretamente nas relações estabelecidas entre clientes e fornecedores, definindo uma hierarquia na cadeia de fornecimento e uma redução no número de fornecedores das montadoras (Quintão, 2003). Particularmente no Brasil, grandes mudanças na indústria se iniciaram nos anos 1990, que ficaram caracterizados por um cenário otimista na indústria automotiva nacional, em virtude da abertura comercial e de vultosos investimentos que possibilitaram ao setor a adoção de novos processos de distribuição e integração da cadeia de suprimentos (produção enxuta, reengenharia, terceirização, just in time, etc.), aumentando a qualidade, reduzindo custos e o tempo de entrega. O Brasil possui, hoje, uma considerável competência na indústria automobilística e desenvolveu um grande número de fornecedores locais (Gobbo, Rodrigues, Gobbo, \& Fusco, 2010). Desse modo, de acordo com Bahia e Domingues (2010), houve uma busca de especialização por parte das montadoras, que refletiu na redução da quantidade de fornecedores, a partir da segunda metade da década de 1990.

No primeiro elo deste setor ficam os chamados sistemistas, responsáveis pela entrega de sistemas de peças completos às montadoras (módulos); no nível dois encontram-se os produtores de peças e componentes que fornecem aos sistemistas; no terceiro e no quarto níveis localizam-se fabricantes de peças isoladas e os produtores de matérias-primas. A relação autopeça/montadora Revista de Administração e Inovação, São Paulo, v. 10, n.1, p. 119-140, Jan./Mar. 2013. 
contrapõe grandes compradores de um lado e um grande número de empresas sem poder de influência na formação de preços, de outro (Ministério do Desenvolvimento, Indústria e Comércio Exterior [MDIC], 2003). Dessa forma, os fornecedores são forçados a atingir um preço cada vez menor para as montadoras (Rachid, 2000).

De acordo com Carvalho (2006), essa capacidade das montadoras pode ser explicada pela configuração da cadeia automotiva nacional, em que as mesmas transferem aos fornecedores o ônus das estratégias competitivas. Desse modo, nas relações entre as montadoras e os sistemistas de grande porte, há um mercado que converge, em termos de requerimentos básicos para fornecimento, ligado ao coprojeto, ou codesign,com os grandes fornecedores (Quintão, 2003).

De acordo com Cardoso (2006), a relação entre fornecedores tem variações em diversos níveis da cadeia, dependendo do porte do sistemistas. Conforme Humphrey e Salerno (1999), algumas companhias adotaram, no Brasil, a política de um fornecedor, enquanto outras adotaram mais de um para fortalecer seu poder de barganha. Os autores ainda destacam quatro fatores fundamentais na escolha do fornecedor por parte da montadora: qualidade, comprometimento com o novo sistema de fornecimento, recursos de engenharia e preço. Esses fatores foram confirmados pelo entrevistado da montadora pesquisada: "Veja. A política nossa da empresa é de trabalhar com mais de um parceiro e, aí, vai ter vários aspectos, né? Aspectos comerciais, aspectos tecnológicos, aspectos estratégicos, de você ter mais de um fornecedor. Então, essa é a política, era quando a gente começou, nos início dos anos 2000, a desenvolver oflex e continua sendo hoje. Hoje, nós temos os três fornecedores e temos os três como parceiros. O custo é importantíssimo e tanto é que os três são extremamente competitivos. Hoje, eles estão no mercado e estão fornecendo pra gente porque eles são competitivos. Além disso, eles têm outro ponto muito forte, todos os três. Eles têm uma estrutura de engenharia, aqui no Brasil, que atende plenamente às necessidades nossas. Isso é muito importante” (montadora A).

Desse modo, pode-se afirmar que as relações de colaboração da indústria variam conforme a posição na cadeia de fornecimento e que as montadoras conseguem a padronização de componentes, devido ao fator custo. Conforme Salerno et al. (2002), os contratos têm cláusula de 'manutenção da competitividade do fornecedor', obrigando-o a se manter dentro de padrões de qualidade e preços vantajosos para as montadoras, sob pena de perda de contrato. Nesse sentido, as transações assumem a tipologia contratual arm's-length. Nessa tipologia, os custos de transação estão associados ao cumprimento de contratos, sendo que a firma com menor custo de troca (montadora) pode manter a outra para extrair ganhos adicionais da transação (Veloso \& Fixson, 2001). É isso o que se observa no seguinte trecho de entrevista: "A montadora, ela 'tá vendo a redução de custo, mas, por outro lado, o fornecedor, ele tem mecanismo pra se proteger e eu sei que, no caso da (montadora $x$ ), eles têm uma Revista de Administração e Inovação, São Paulo, v. 10, n.1, p. 119-140, Jan./Mar. 2013. 
política assim: eles desenvolvem dois, três fornecedores pra mesma peça. Em função de eles terem volume, então, eles têm duas ou três opções. Aí, o que acontece? Se um fornecedor, ele... não dá conta, ele fala: 'não, meu preço é X e tem um outro que é 10\%...' Gera uma competição já entre esses fornecedores" (fornecedora Gama).

É importante ressaltar que a abordagem da gestão das cadeias pode estar relacionada com suas características. Amato e Olave (2005) consideram que há cadeias controladas pelos produtores, como a automobilística (relacionamento vertical) e cadeias controladas pelos compradores (relacionamento horizontal), como a de vestuário. Souza, Arbage e Corazza (2006) afirmam que agentes econômicos da indústria automotiva estão assumindo a coordenação de todo ou de parte do sistema produtivo. Embora haja relacionamentos de longo prazo entre montadora e fornecedor, motores de maior complexidade tendem a ser produzidos internamente, enquanto os de menor complexidade são externalizados (Bigelow \& Argyres, 2008), o que pode ser observado no seguinte trecho: "O sistema flex, inicialmente, era vendido fechado às montadoras, que instalavam nos veículos. Atualmente, as montadoras conseguem coordenar a cadeia e estabelecer padrões específicos para os veículos, em termos de características... As montadoras podem adquirir a tecnologia de qualquer fornecedor que ofereça mais vantagens em preços, ou atenda às especificações das montadoras. Nesse sentido, a busca dos sistemistas é a diferenciação de componentes, enquanto as montadoras procuram a padronização. Geralmente, o cliente final do sistemista é a montadora” (fornecedora Gama).

Maia e Cerra (2008) afirmam que as empresas automotivas utilizam contratos formais para regerem as suas transações de fornecimento. Esse fato está fortemente relacionado à escolha da forma de relação híbrida da montadora com seus fornecedores, dado que a cooperação pode conferir os benefícios de proximidade, da troca de conhecimentos e da dependência presentes na integração vertical, enquanto a competência latente pode trazer os benefícios de competição por preços e condições de fornecimento presentes no mercado. Dessa forma, observa-se que as características das transações da tecnologia flex-fuel são mistas - ou feitas por contrato -, mesclando relações de mercado (por parte da montadora na aquisição da tecnologia) e aspectos relacionais, para concepção e desenvolvimento da tecnologia. Conforme Menard (1996 citado em Conejero, Sai, Pinto, \& Iguchi, 2008), as formas híbridas de governança têm dependência bilateral forte o suficiente para requerer algum tipo de coordenação.

\subsection{A Tecnologia Flex-Fuel: a Racionalidade Limitada}

Revista de Administração e Inovação, São Paulo, v. 10, n.1, p. 119-140, Jan./Mar. 2013. 
A racionalidade limitada refere-se ao comportamento que pretende ser racional, mas o consegue de forma contida (Richetti \& Santos, 2000). Ao assumir como verdadeiro o pressuposto da racionalidade limitada do ser humano, a qualidade das informações passa, verdadeiramente, a ser uma variável chave para a tomada de decisões (Faria, Ferreira, Santos, \& Silveira, 2010). No contexto da tecnologia flex-fuel havia a dúvida sobre a viabilidade do projeto, conforme se observa no seguinte trecho de entrevista: "Na análise do mercado automotivo brasileiro dos últimos 30 anos, nós vimos que, no final dos anos (19)70 o Brasil desenvolveu o..., Brasil lançou aquele famoso programa chamado PROÁLCOOL. Nos anos (19)80, 95\% dos carros vendidos no Brasil eram a álcool O que aconteceu no final da década de 80, começo da década de (19)90? Sumiu álcool no mercado, não tinha mais álcool nos postos, gerando aquele famoso fenômeno de desespero nos usuários de carros usados que não tinham mais o combustivel para abastecer. Em consequência, nos anos 90, no final dos anos 90, pra chegar naquele ano (19)99, o percentual de carros a álcool vendido no Brasil era menor de 1\%. Muito pequeno, ou seja, desenvolveu-se uma estratégia do carro a álcool e o produto está morrendo porque o usuário não quer mais o carro a álcool e vai dizer que vai acontecer de novo o que aconteceu” (fornecedora Alfa ).

Conforme Martins, Xavier e Sproesser (2010), a racionalidade limitada admite que os agentes econômicos atuam sem o conhecimento completo das opções disponíveis e de todas as suas consequências. Além do mais, a obtenção das informações é custosa como se observa no seguinte trecho: "No início do flex, a gente tinha muito do know-how que a gente já tinha adquirido quando era a parte carburada, né? E do muito know-how daquela dos motores só álcool, $100 \%$ álcool, que a gente buscou nas gavetas literalmente. Não era computador. A gente tinha este problema que a gente tinha que resolver, aí a gente resolvia. Então, fomos buscando com os fornecedores a solução para alguns problemas, alguns anseios que a gente tinha dos motores anteriores" (montadora A).

No entanto, a tecnologia se mostrou viável pela ampla aceitação do mercado, forçando a adesão das montadoras,o que comprova a racionalidade limitada dos agentes.

"São poucas montadoras que não têm plataforma flex. Esse ano, acho que já, praticamente, só os coreanos, que 'tão entrando agora, que não têm, não têm o motor flex. Então, assim, a montadora se viu praticamente forçada a entrar nesse mercado" (montadora B).

\section{CONSIDERAÇÕES FINAIS}

Revista de Administração e Inovação, São Paulo, v. 10, n.1, p. 119-140, Jan./Mar. 2013. 
Esse trabalho foi realizado com o objetivo de identificar o surgimento da tecnologia flex-fuel sob a perspectiva da teoria dos custos de transação. O desenvolvimento do flex-fuel ocorreu em parceria com uma montadora de automóveis e visou, primordialmente, à adequação do uso da tecnologia a condições locais. Nesse sentido, o lançamento do primeiro modelo bicombustível, em 2003, no Brasil, representou o sucesso da indústria automobilística na acumulação de conhecimentos entre montadoras e fornecedores automotivos. Diante dos dados apresentados, observou-se que, no processo de geração da tecnologia flex-fuel,as características da TCT - racionalidade limitada, frequência da transação, especificidade de ativos, e oportunismo - estão presentes.

$\mathrm{Na}$ perspectiva da TCT, a tecnologia flex-fuel constitui-se como um ativo com alta especificidade humana, pois as tecnologias automobilísticas dependem de conhecimentos específicos em áreas diversas, tornando necessária a especialização dos fornecedores. No entanto, a tecnologia flex é um ativo que tem baixa especificidade física, pois é padronizada e pode ser 'encontrada' no mercado com fornecedores distintos. Adicionalmente, os resultados demonstraram a presença de racionalidade limitada, devido à incerteza acerca da viabilidade da tecnologia e ao alto custo de informações necessárias para a sua elaboração.

A tecnologia flex-fuel é resultado das mudanças que provocaram modificações nas estruturas de governança da indústria automotiva. Esse contexto demonstra que as montadoras (por terem o knowhow do motor e poder na cadeia produtiva) têm a capacidade de ditar normas e regras para as transações. Dessa forma, observou-se que as transações da tecnologia flex-fuel foram feitas de forma híbrida, para que a montadora se resguardasse de práticas oportunistas, mesclando relações de mercado (por parte da montadora na aquisição da tecnologia) e hierarquia (para concepção da tecnologia). Nesse sentido, as transações assumem a tipologia contratual arm's-length, pela qual os custos de transação estão associados ao cumprimento de contratos.

Este estudo pretende gerar, ao menos, uma contribuição. Essa contribuição encontra-se associada ao esforço de se verificar a geração de uma inovação a partir da abordagem relacional focada nos custos de transação, buscando identificar elementos subjetivos a esse processo, como a racionalidade limitada e o oportunismo. A visão da TCT abrange aspectos da economia institucional que, para Furtado (2002), é útil para a análise do processo de inovação porque aspectos institucionais têm forte influência na forma como o novo conhecimento chega ao mercado e envolvem uma série de elementos, tais como: (i) atores, (ii) papéis/funções, (iii) regras e (iv) mecanismos de coordenação ou governança. A literatura sobre a difusão e inovação tecnológica sugere a importância do ambiente institucional (que englobe relações de mercado e nãomercado) para a comercialização da inovação Revista de Administração e Inovação, São Paulo, v. 10, n.1, p. 119-140, Jan./Mar. 2013. 
(Lynn, Reddy, \& Aram, 1996). Na visão institucional, parte-se da premissa de que as organizações buscam por meio da inovação um lucro extraordinário, de forma que o comportamento organizacional está condicionado à busca por uma maior competitividade (Boehe \& Zawislak, 2007). Assim, a importância do papel das instituições dentro da dinâmica da inovação é amplamente reconhecido na atualidade e o principal beneficio da abordagem institucional é indicar claramente a existência de trajetórias sociais da inovação que são determinadas pelo contexto social no qual os diversos agentes e as empresas operam (Coriat \& Weinstein, 2002).

Paralelamente, a principal limitação do estudo está no foco exclusivo da pesquisa em apenas uma tecnologia, o que impossibilita identificar mudanças de longo prazo, tanto na geração de tecnologias quanto nos aspectos de governança das transações no âmbito da indústria automobilística. A partir disso, sugerem-se estudos mais amplos a partir desses elementos subjetivos presentes nos custos de transação dos processos de inovação tecnológica flex-fuel, sobretudo em uma perspectiva longitudinal, reavaliando o contexto atual e as prospecções de cenários futuros. Adicionalmente, sugerem-se estudos com outros tipos de tecnologias e em outras indústrias, visto que este contexto e seus fenômenos associados podem apresentar a tendência de se manifestar em outros ambientes.

\section{REFERÊNCIAS}

Aguiar, E. C. (2001). Relações de fornecimento na indústria automobilística paranaense: o caso Chrysler-Dana. (Dissertação de Mestrado). Universidade Federal do Rio Grande do Sul, Porto Alegre RS, Brasil.

Alves, A. Filho, Cerra, A., Maia, J., Sacomano, M., Neto, \& Bonadio, P. (2004). Pressupostos da gestão da cadeia de suprimentos: evidências de estudos sobre a indústria automobilística. Gestão \& Produção, 11(3), 275-288.

Alves, M. L., \& Brandão, L. E. T. (2007). Automóvel flex fuel: quanto vale a opção de escolher o combustível? Anais do Encontro da Associação Nacional de Pós-Graduação e Pesquisa em Administração, Rio de Janeiro, RJ, 31.

Amato, J., Neto, \& Olave, M. E. L. (2005). A formação de redes de cooperação e clusters em países emergentes: uma alternativa para PMEs no Brasil. In J. Amato, Neto (Org.), Redes entre organizações: domínio do conhecimento e da eficácia operacional (pp. 68-93). São Paulo: Atlas.

Bahia L. D., \& Domingues, E. P. (2010). Estrutura de inovações na indústria automobilística brasileira (IPEA Texto para Discussão, 1472). Brasília, DF: IPEA.

Bardin, L. (1979). Análise de conteúdo. Lisboa: Ed. 70.

Revista de Administração e Inovação, São Paulo, v. 10, n.1, p. 119-140, Jan./Mar. 2013. 
Barney, J. B., \& Hesterly, Y. W. (2006). Economia das organizações: entendendo a relação entre as organizações e a análise econômica. In S. R. Clegg, C. Hardy, \& W. R. Nord (Eds.), Handbook de estudos organizacionais (Vol. 3, pp. 131-185). São Paulo: Atlas.

Bigelow, L. S., \& Argyres, N. (2008). Transaction costs, industry experience and make-or-buy decisions in the population of early US auto firms. Journal of Economic Behavior \& Organization, 66(3/4), 791-807.

Boehe, D. M., \& Zawislak, P. A. (2007). Influências ambientais e inovação de produtos: estudo de casos em subsidiárias de multinacionais no Brasil. Revista de Administração Contemporânea, 11(1), 97-117.

Cardoso, A. M. (2006). A nova face indústria automobilística brasileira ou a tese da convergência revisitada. In A. Cardoso, \& A. Covarrubias (Orgs.), A indústria automobilística nas Américas: a reconfiguração estratégica e social dos atores produtivos (pp. 79-112). Belo Horizonte: UFMG/IUPERJ.

Carvalho, R. Q. (2006). Relações interfirmas governança e desenvolvimento tecnológico na cadeia automotiva brasileira. In A. Cardoso, \& A. Covarrubias (Orgs.), A indústria automobilística nas Américas: a reconfiguração estratégica e social dos atores produtivos (pp. 63-78). Belo Horizonte: UFMG/IUPERJ.

Cerra, A. L. (2005). Estratégias tecnológicas em cadeias de suprimentos da indústria automobilística brasileira: estudos de caso em empresas do segmento de motores de automóveis. (Tese de Doutorado). Universidade Federal de São Carlos, São Carlos, SP, Brasil.

Cerra, A. L., Maia, J. L., \& Alves, A. G., Filho. (2007). Aspectos estratégicos, estruturais e relacionais de três cadeias de suprimentos automotivas. Revista Gestão e Produção, 14(2), 253265.

Conejero, M. A., Sai, E. J., Pinto, M. J. A., \& Iguchi, R. K. S. (2008). Arranjos contratuais complexos na transação de cana à usina de açúcar e álcool: um estudo de caso no Centro-Sul do Brasil. Anais do Encontro da Associação Nacional de Pós-Graduação e Pesquisa em Administração, Rio de Janeiro, RJ, 32.

Consoni, F. L. (2004). Da tropicalização ao projeto de veículos: um estudo das competências em desenvolvimento de produtos nas montadoras de automóveis no Brasil. (Tese de Doutorado). Universidade Estadual de Campinas, Campinas, SP, Brasil.

Coriat, B., \& Weinstein, O. (2002). Organizations, firms and institutions in the generation of innovation. Research Policy, 31(2), 273-290.

Costa, S. J., Carvalho, J. M., \& Thomé, K. M. (2008). Configurações de transação da cadeia de produção e comercio do álcool combustível: estudo de caso do vale do São Patrício - GO. Anais do Congresso da Sociedade Brasileira de Economia, Administração e Sociologia Rural, Rio Branco, $\mathrm{AC}, 46$. 
Crispim, S., \& Toledo, R. M. (2003). Mudanças no cenário competitivo do setor automobilístico e o caso único de consórcio modular: a VW de Resende. Anais do Encontro da Associação Nacional de Pós-Graduação e Pesquisa em Administração, Atibaia, SP, 27.

Delgado, R. C. O. B., Araujo, A. S., \& Fernandes, V. J., Jr. (2007). Properties of Brazilian gasoline mixed with hydrated ethanol for flex-fuel technology. Fuel Processing Technology, 88(4), 365-368.

Di Giulio, G. (2006). Motor bicombustível ganha cada vez mais consumidores. Inovação Uniemp, 2(1), 38-40.

Dias, A. V. C. (2003). Produto mundial, engenharia brasileira: integração de subsidiárias no desenvolvimento de produtos globais no setor automotivo. (Tese de Doutorado). Universidade de São Paulo, São Paulo, SP, Brasil.

Dias, A. V. C., \& Salerno, M. S. (1998). Novos padrões de relacionamento entre montadoras e autopeças no Brasil: algumas proposições. Anais do Encontro Nacional de Engenharia de Produção, Niterói, RJ, 28.

Faria, E. R., Ferreira, M. A. M., Santos, L. M., \& Silveira, S. F. R. (2010). Fatores determinantes na variação dos preços dos produtos contratados por pregão eletrônico. Revista de Administração Pública, 44(6), 1405-1428.

Ferrato, E., Carvalho, R. Q., Spers, E. E., \& Pizzinatto, N. K. (2006). Relacionamento interorganizacional e hold-up no setor automotivo: uma análise sob o enfoque da economia dos custos de transação. Revista de Gestão USP, 13(1), 75-87.

Ferreira, M. P., \& Serra, F. A. R. (2010). Make or buy in a mature industry? Models of client supplier relationships under TCT and RBV perspectives. Brazilian Administration Review, 7(1), 22-39.

Furtado, A. T. (2002). Mudança institucional e inovação na indústria brasileira de petróleo. Revista Brasileira de Energia, 9(1), 1-12.

Gatti, W., Jr., \& Yu, A. S. O. (2011). As transformações do conhecimento no processo de inovação: o desenvolvimento da tecnologia flexfuel nos sistemistas brasileiros. Anais do Encontro da Associação Nacional de Pós-Graduação e Pesquisa em Administração, Rio de janeiro, RJ, 35.

Gobbo, S. C. O., Rodrigues, J. S., Gobbo, J. A., Jr., \& Fusco, J. P. A. (2010). Uma análise das estratégias de manufatura adotadas por seis montadoras da indústria automobilística mundial. Gestão da Produção, Operações e Sistemas, 5(3), 11-28.

Humphrey, J., \& Salerno, M. S. (1999). Globalisation and assembler-supplier relations: Brazil and India. Les Actes du Gerpisa, 25, 41-63.

Kupfer, D., \& Hasenclever, L. (2002). Economia industrial. Rio de Janeiro: Campus.

Lima J. G. (2006). A riqueza é o saber. Recuperado em 04 de setembro, 2008, de http://veja.abril.com.br/010206/p_090.html.

Revista de Administração e Inovação, São Paulo, v. 10, n.1, p. 119-140, Jan./Mar. 2013. 
Lynn, L. H., Reddy, N. M., \& Aram, J. D. (1996). Linking technology and institutions: the innovation community framework. Research Policy, 25(1), 91-106.

Maia, J. L., \& Cerra, A. L. (2008). Relacionamentos entre empresas na cadeia de suprimentos de uma montadora de motores - uma discussão a partir da teoria de custos de transação. Revista de Economia, 34(1), 51-75.

Martins, R. S., Xavier, W. S., \& Sproesser, R. L. (2010). Custo de transação nas operações de exportação de café na região sul de Minas Gerais. Organizações Rurais \& Agroindustriais, 12(3), 411-422.

McIvor, R. (2009). How the transaction cost and resource-based theories of the firm inform outsourcing evaluation. Journal of Operations Management, 27(1), 45-63.

Mello, A. M., Vasconcellos, L. H. R., \& Marx, R. (2005). Estariam as montadoras abrindo mão de suas competências essenciais no desenvolvimento de motores? Um estudo de caso do primeiro veículo nacional bicombustível. Anais do Encontro da Associação Nacional de Pós-Graduação e Pesquisa em Administração, Brasília, DF, BR, 29.

Mello, A. M., Vasconcellos, L. H. R., \& Marx, R. (2006). A iniciativa do terceirizado. HSM Management Update, 36, 1-5.

Mesquita, D. L., \& Sugano, J. Y. (2011). The flex-fuel technology building process in Brazil: an analysis from the perspective of business platform. African Journal of Business Management, 5(20), 8100- 8109.

Ministério do Desenvolvimento, Indústria e Comércio Exterior. (2003). Fórum de competitividade da cadeia produtiva automotiva. Recuperado em 05 de novembro, 2010, de http://ce.mdic.gov.br/remtech/docs/MDIC\%20\%20Diagnostico\%20do\%20Cadeia\%20Produtiva\%2 OAutomotiva.doc.

Piacente, E. A. (2006). Perspectivas do Brasil no mercado internacional de etanol. (Dissertação de Mestrado). Universidade Estadual de Campinas, Campinas, SP, Brasil.

Pinheiro, I. A. (1999). A externalização de atividades: fundamentos e experiências no setor de autopeças gaúcho. Revista de Administração Contemporânea, 3(2), 137-165.

Quintão, R. A. C. (2003). Coordenação e aperfeiçoamento tecnológico na cadeia automotiva brasileira: os reflexos para as pequenas e médias empresas produtoras de autopeças. (Dissertação de Mestrado). Universidade Estadual de Campinas, Campinas, SP, Brasil.

Rachid, A. (2000). Relações entre grandes e pequenas empresas de autopeças: um estudo sobre a difusão de práticas de organização da produção. (Tese de Doutorado). Universidade Estadual de Campinas, Campinas, SP, Brasil.

Richetti, A., \& Santos, A. C. (2000). O sistema integrado de produção de frango de corte em minas Gerais: uma análise sob a ótica da ECT. Organizações Rurais \& Agroindustriais, 2(2), 34-43.

Revista de Administração e Inovação, São Paulo, v. 10, n.1, p. 119-140, Jan./Mar. 2013. 
Rocha, W. F., Jr., Silva, C. L., Bittencourt, M. V. L., \& Mascena, C. M. (2012). Transações entre suinocultores e agroindústrias no estado de Santa Catarina (Brasil): um exame de contratos sob enfoque institucional. Revista do Desenvolvimento Regional, 17(2), 229-248.

Rodrigues, C. M. T., Aguiar, E. C., \& Macohin, G. A. (2004). Relações cliente - fornecedor na indústria automobilística paranaense: o caso Chrysler e Dana. Anais do Encontro Nacional de Engenharia de Produção, Florianópolis, SC, 24.

Salerno, M. S., Marx, R., Zilbovicius, M., Graziadio, T., Dias, A. V. C., Muniz, S. T. G., et al. (2002). A nova configuração da cadeia automotiva brasileira (Relatório de Pesquisa da Escola Politécnica da Universidade de São Paulo). São Paulo: USP.

Segre, L. M., Roldan, O. F. M., \& Dumans, G. (1998). Inovações tecnológicas no setor automobilístico: impactos e tendências. Anais do Encontro Nacional de Engenharia de Produção, Niterói, RJ, 28.

Seth, A., \& Thomas, H. (1994). Theories of the firm: implications for strategy research. Journal of Management Studies, 31(2), 165-192.

Souza, R. S., Arbage, A. P., \& Corazza, C. (2006). Gerenciamento da cadeia de suprimentos de engenhos de arroz no Rio Grande do Sul: um estudo à luz da Economia dos Custos de Transação. Organizações Rurais \& Agroindustriais, 8(1), 49-57.

Teixeira, E. C. (2005). O desenvolvimento da tecnologia flex-fuel no Brasil. São Paulo: Instituto DNA Brasil.

Torres, R L. (2011). A indústria automobilística brasileira: uma análise da cadeia de valor. (Dissertação de Mestrado). Universidade Federal de Santa Catarina, Florianópolis, SC, Brasil.

Triviños, A. N. S.(1987). Introdução à pesquisa em ciências sociais: a pesquisa qualitativa em educação. São Paulo: Atlas.

Veloso, F., \& Fixson, S. (2001). Make-buy decisions in the auto industry: new perspectives on the role of the supplier as an innovator. Technological Forecasting and Social Change, 67(2/3), 239257.

Vergara, S. C. (2006). Métodos de pesquisa em administração (2a ed.). São Paulo: Atlas.

Vieira, C. R. B. (2001). A cadeia totalmente integrada na indústria automotiva: uma análise das exigências de fornecimento nas empresas de autopeças do Rio Grande do Sul. (Dissertação de Mestrado). Universidade Federal do Rio Grande do Sul, Porto Alegre, RS, Brasil.

Williamson, O. E. (2005). Transaction cost economics and business administration. Scandinavian Journal of Management, 21(1), 19-40.

Womack, J. P., Jones, D. T., \& Roos, D. (2004). A máquina que mudou o mundo (4a ed.). Rio de Janeiro: Campus.

Revista de Administração e Inovação, São Paulo, v. 10, n.1, p. 119-140, Jan./Mar. 2013. 
Yu, A. S. O., Nascimento, P. T., Silva, L. L. C., Camargo, A. S., Jr., Duranti, C. M., \& Moura, C. B. (2010). Evolution of flex-fuel technology: a case study on Volkswagen Brazil. Anais do Encontro da Associação Nacional de Pós-Graduação e Pesquisa em Administração, Rio de Janeiro, RJ, 34.

\title{
THE DEVELOPMENT OF INNOVATION PROCESSES FROM THE PERSPECTIVE OF TRANSACTION COSTS THEORY: THE CASE OF THE FLEX-FUEL TECHNOLOGY
}

\begin{abstract}
The purpose of this paper is to analyze the creation of the flex-fuel technology under the perspective of Economy Transaction Cost (ECT). To achieve this purpose, the main actors involved in the technology development were interviewed, articulating four analytic categories to identify how ECT is structured in the flex-fuel technology: bounded rationality; frequency transaction; asset specificity; and opportunism. We conclude that the automakers had the capacity to elaborate contracts mixing hybrid relationships between markets and hierarchies. The main contribution of this paper consists of the analysis of transaction costs in the flex-fuel technology development, a fact not widely studied in Brazil.
\end{abstract}

Key- words: Economy Transaction Cost; flex-fuel technology; innovation.

Data do recebimento do artigo: 29/10/2012

Data do aceite de publicação: 23/01/2013

Revista de Administração e Inovação, São Paulo, v. 10, n.1, p. 119-140, Jan./Mar. 2013. 